\title{
Investigation of Prospective Kickboxing Coaches' Self-Esteem in Decision Making and Decision Making Styles
}

\author{
Eyyup Nacar \\ Correspondence: Eyyup Nacar, Frrat University, Faculty of Sport Sciences, 23000, Elazığ-Turkey. \\ Received: February 21, 2019 \\ Accepted: March 21, 2019 Online Published: April 2, 2019 \\ doi:10.11114/jets.v7i5.4193 \\ URL: https://doi.org/10.11114/jets.v7i5.4193
}

\begin{abstract}
Decision refers to the act of choosing the most appropriate type of action possible according to present possibilities and conditions in order to achieve an aim. Decision making covers all cognitive and behavioral effort for choosing and preferring in the face of various situations and events. Starting from this point of view, in our study, it was aimed to investigate prospective kickboxing students' self-esteem in decision making and decision making styles.

The study included 62 voluntary prospective coaches, who participated in a kickboxing coaching in the city center of Elazığ in 2017. In order to obtain personal information from the participant prospective coaches in the study, a personal information form (age, gender, years of doing sports) was formed. In order to investigate the self-esteem in decision making and decision making styles of prospective kickboxing coaches, the Melbourne Decision Making Questionnaire, which was originally developed by Mann et al., (1998) and adapted into Turkish by Deniz (2004), was utilized. The obtained data were evaluated by using SPSS statistics package software and the level of significance was regarded as $\mathrm{p}<0.05$.

As a result of the study, according to participants' variables of age, gender and years of doing sports, the comparison of prospective teachers' decision making and decision making style mean scores did not constitute a statistically significant difference. The self-esteem levels of coaches in decision making were observed to be significantly high.
\end{abstract}

Keywords: coach, kickboxing, decision making, sports

\section{Introduction}

Coaches are individuals who have sufficient information and experience in their own fields and transfer those information and experience to athletes by effective communication while developing themselves through science and training their athletes for the desired aim (Temel, 2010).

In a general definition, coaches are individuals who help athletes carry their performance and potential to their peaks, actualize their physical, social, emotional and mental capacities and prepare them for matches (Ulukan, 2006).

Kickboxing is defensive combat sport based on punching and kicking, which is historically developed from Karate, Thai Boxing and westers boxing sports (ttp/www.kikboks.gov.tr/Kickboks Tarihçesi htm, 12.04.2018 00:44).

Decision refers to the act of choosing the most appropriate type of action possible according to present possibilities and conditions in order to achieve an aim. Decision making covers all cognitive and behavioral effort for choosing and preferring in the face of various situations and events. Starting from this point of view, in our study, it was aimed to investigate prospective kickboxing students' self-esteem in decision making and decision making styles (Kuzgun, 2000, Yiğit, 2005).

Decision making is to adapt to a certain type of action. No matter how large or small its extent is, it is making a sensible and emotional commitment (Çimen, 1999).

In order for people to make a decision among many options safely, people need to make various attempts. These attempts include

1. Gathering complete and correct information about the matter,

2. Rendering options understandable,

3. Reaching an agreement among options,

4. Learning to live with indefinite situations (uncertainties) and risks 
5. Direct inclusion of the individual in the decision

6. Individual's use of own information and experience while making decisions

7. Appropriateness of positive or negative situations brought by the decision for the individual's behavioral structure (Carney, 1995).

\section{Process of Decision Making}

Individuals make decisions in various conditions and during various periods. Therefore, decision making may not be perceived as a complex situation. However, decision making includes mental states that combine weak and strong aspects of mind. It is important to understand and interpret decision making and situations involved in this process. The fact that individual differences exist in decision making is reflected as differences in decision making styles. The initial focus in decision making studies has been individuals' interests, what they base their decisions on and how they make decisions (Clemen, Reilly, 2001, Ormand and ark.1991).

It is possible to divide an individual's process of forming theoretical perceptions about decision making into two groups as approaches of focusing on product and process. Product focused approach includes the perceptions of explaining the results revealed by the results of the process of decision making and the belief that process of decision making would provide understanding. The basis of this approach is the results of the decision to be made and correctly estimating these results. In the processed focused approach in decision making, the main perception is that the understanding of the decision making process would provide the correct prediction of the revealed results. In this approach, which describes the decision making process basically, there is a belief that obtaining detailed information about how the decision would reveal how decisions would be made in the most suitable way (Ersever, 1996). Therefore, most individuals are observed using their cognitive capacities not to its limit and choosing brief and short ways (Kökdemir, 2003).

\section{Decision Making Styles}

Individual characteristics are closely related to the decision making styles of individuals. While the initial theoretical explanations of decision making styles conceptually focus on behaviors rather than general characteristics, several researchers focus on information collected by individuals and process information (Payne, 1993). While individuals collect information in the decision making process, they consider previously established cognitive styles to internalize this information and separate both the concepts and the information.

In decision making studies, the general focus is on decision making styles and decision making strategies. The information collected and evaluated in decision making process affects decision making styles of individuals (Phillips, Pazienza, Walsh, 1984).

Research reported that social factors are important factors in decision making styles and individuals' feeling of responsibility toward their families, friends and acquaintances affects how the decision will be made (Norfolk, 1989).

The researchers who evaluate decision making styles cognitively state nine structures as choice, understanding, creative problem solving, reconciliation, evaluation of results, correct choice, reliability, determination and affiliation (Terakya, 1998)

Choice: It is the precondition in decision making skills. Control of decisions is related to impulsive control and self-esteem. In adolescents' decision, this can generally be postponed due to the requirement of adapting to friends and social environment.

Understanding: Cognitively, decision making is understanding its effectiveness. Skills such as reading, remembering and problem solving may be required in conducting cognitive processes.

Creative Problem Solving: It includes concepts to achieve the aim, such as the definition problem, forming alternatives, taking necessary steps to form new alternatives by exhibiting a creative thought.

Reconciliation: It is the agreement on an acceptable solution in any topic or situational disagreement.

Evaluation of Results: It is the level of thinking about the results of actions for one's own and others.

Correct Choice: It is the precondition for obtaining information effectively and sensibly. Individuals, who make decisions as solvers, are those who use problem solving strategies flexibly.

Reliability: It is the ability to evaluate the reliability of information in choosing among alternatives.

Determination: Individuals who make decision skillfully are expected to be consistent in choices. Individuals further in adolescence may be more consistent in decisions.

Affiliation: It is about the binding of decisions. With increased age, high levels of increases in competence levels in decision making situations can be observed (Phillips, Pazienza, Ferrin, 1984). 
Several researchers have classified individuals decision making as spontaneous-systematic decision making and introverted-extroverted decision making. In spontaneous-systematic dimension, how the information obtained and how it is included in the process is determined.

Individuals with spontaneous decision making style make decisions quickly. Individuals who act systematically collect the information about the decision more carefully and meticulously and they approach to decision making process in a more rationalist way. In introverted-extroverted dimension, the way that individuals obtain information is emphasized. Individuals with extraverted decision making style discuss decision making processes loudly.

Individuals with introverted style, contrary to individuals with extraverted style, stay quiet and evaluate this process with a belief that this process is private for themselves. It is emphasized that these decision making styles are different from each other and none of them is better or worse than each other (Tiryaki, 1991).

Researchers who describe decision making styles as learned habits believe the facts that definition of options while reaching decisions and the amount of thinking during a decision play key roles in differences between styles.

Self-esteem in decision making: It covers various situations that include the collected information and various alternative situations thought.

Moreover, researchers have stated four types of decision making styles (Shiloh, 2001 Sinangil, 1993). These are as the following.

Careful Decision Making Style: In this decision making style, individuals choose the most suitable alternative to the situation by conducting research and evaluation regarding the situation to make a decision about. Individuals with careful decision making style exhibit a more caring attitude.

Avoidant Decision Making Style: In this decision making style, individuals keep away from decision to avoid decision making. Individuals with avoidant decision making style exhibit tendencies to escape from the responsibility of decision making.

Postponing Decision Making Style: Individuals suspend their problems and they prefer to postpone thinking about the problem and putting it into action by postponing it to a future date.

Panic Decision Making Style: In this decision making style, individuals make decision with their internal emotions and insight. Individuals with panic decision making style are quicker compared to others and they use their insight (Shiloh, 2001 Sinangil, 1993).

\section{Decision Making in Sports}

When faced with the situation of decision making process, it is not always possible to evaluate all the characteristics of options and all results obtained (Norfolk, 1989).

In decision making process, there are many basic cognitive mechanisms activated for the actualization of the process. Especially, when a problem is presented, the most important characteristics are determined and previous information is recalled in the brained, actualizing a meaningful organization of this information. All of the information resources are evaluated, combined and the decision is made (Phillips, Pazienza, Ferrin, 1984).

Coaches evaluate motor behavior of athletes during matches to ensure that their athletes reach a good level of performance and to support their athletes (Deniz, 2002).

\section{Material and Method}

In this study, the survey method was utilized in order to evaluate self-esteem in decision making and decision making styles of prospective kickboxing coaches. In this study, 62 prospective coaches, who participated in a coaching course in the city of Elazığ in 2017, participated voluntarily.

\section{Data Collection Tools}

In order to obtain personal information from prospective kickboxing coaches in the study, a personal information form (age, gender, years of doing sports) was used while "Melbourne Decision Making Questionnaire" was used in order to evaluate the self-esteem in decision making and decision making styles of prospective kickboxing coaches.

\section{Melbourne Decision Making Questionnaire}

The Melbourne Decision Making Questionnaire, which was originally developed by Mann et al. (1998) and was adapted into Turkish by Deniz in the validity and reliability study (2004), was utilized (Deniz, 2004).

The validity and reliability study of the Melbourne Decision Making Questionnaire I-II (MDMQ) was conducted by collecting data from 154 students studying in the Department of Computer Systems Teaching and Automotive Teaching in the Education Faculty of Selçuk University during the 2002-2003 education period. 
The Melbourne Decision Making Questionnaire consists of two sections. The I. section includes the determination of self-esteem in decision making. It includes six items, three of which are scored normally while the other three are reverse scored. The "correct" answer is 2 points while "Sometimes Correct" is 1 point and "Incorrect" is 0 points. The maximum score obtained from the questionnaire is 12 points. High scores indicate that self-esteem in decision making is high. The II. Section consists of 22 items and measures decision making styles. It includes four subscales. There are as the following.

Careful Decision Making Style: It includes the careful search for necessary information and making the decision after evaluating alternatives carefully before the individual makes a decision. The factor is expressed with six items $(2,4,6,8,12$, and 16).

Avoidant Decision Making Style: It includes the situations where individuals avoid decision making and tend to leave the decision to others. Thus, they try to avoid decision making by transferring responsibility to others. This factor is expressed with five items $(3,9,11,14,17$, and 19).

Postponing Decision Making Style: Individuals constantly postpone, delay and neglect the decision making process without a valid reason. This factor is expressed with five items $(5,7,10,18$ and 21).

Panic Decision Making Style: When individuals are faced with a decision situation, they feel that they are under time pressure, exhibit hasty behavior in an effort to achieve quick solutions. This factor is expressed with five items $(1,13,15,20$ and 22).

\section{Statistical Evaluations}

After the research data are obtained, the data were analyzed by using SPSS statistical package software, determining frequencies, distributions, arithmetic means and standard deviations. While conducting statistical evaluations, expert opinion and help were taken. According to several variables of prospective kickboxing coaches, "Decision Making Styles" were evaluated by independent samples t-test while differences between groups and multiple sample comparisons were evaluated by "ANOVA" test. The relationship-correlation levels of research data were determined and interpreted by using "Regression" analysis. The interpretations were supported by tables. The level of significance in the analyses was regarded as $\mathrm{p}<0.05$.

\section{Findings}

Table 1. Distribution Values of Decision Making Styles of Prospective Kickboxing Coaches According to the Variable of Age

\begin{tabular}{|c|c|c|c|c|c|c|}
\hline & Age & $\mathbf{N}$ & $\mathbf{X}$ & Ss & $\mathbf{F}$ & $\mathbf{p}$ \\
\hline \multirow[t]{4}{*}{ Self-Esteem } & $18-21$ & 19 & 10,52 & 0,84 & 1,36 & 0,26 \\
\hline & $22-25$ & 25 & 10,56 & 1,41 & & \\
\hline & 26-above & 18 & 9,94 & 1,51 & & \\
\hline & Total & 62 & 10,37 & 1,30 & & \\
\hline \multirow[t]{4}{*}{ Careful } & $18-21$ & 19 & 8,94 & 2,09 & 2,97 & 0,05 \\
\hline & $22-25$ & 25 & 9,92 & 2,64 & & \\
\hline & 26-above & 18 & 10,72 & 1,60 & & \\
\hline & Total & 62 & 9,85 & 2,28 & & \\
\hline \multirow[t]{4}{*}{ Avoidant } & $18-21$ & 19 & 2,73 & 2,23 & 0,88 & 0,41 \\
\hline & $22-25$ & 25 & 3,68 & 2,19 & & \\
\hline & 26-above & 18 & 3,22 & 2,62 & & \\
\hline & Total & 62 & 3,25 & 2,33 & & \\
\hline \multirow[t]{4}{*}{ Postponing } & $18-21$ & 19 & 2,57 & 1,30 & 2,93 & 0,06 \\
\hline & $22-25$ & 25 & 3,24 & 2,02 & & \\
\hline & 26-above & 18 & 4,11 & 2,29 & & \\
\hline & Total & 62 & 3,29 & 1,98 & & \\
\hline \multirow{4}{*}{ Panic } & $18-21$ & 19 & 2,73 & 2,02 & 0,13 & 0,87 \\
\hline & $22-25$ & 25 & 3,08 & 2,37 & & \\
\hline & 26-above & 18 & 2,94 & 1,98 & & \\
\hline & Total & 62 & 2,93 & 2,13 & & \\
\hline
\end{tabular}

In the evaluation of the ANOVA analysis results according to gender variable in Table 1, the decision making styles were observed in mean scores of self-esteem, careful, avoidant, postponing and panic subscales $(\mathrm{p}<0.05)$ and no significant difference was observed.

In the evaluation of the ANOVA analysis results according to years of doing sports variable in Table 2, the decision making styles were observed in mean scores of self-esteem, careful, avoidant, postponing and panic subscales $(\mathrm{p}<0.05)$ and no significant difference was observed. 
Table 2. Distribution Values of Decision Making Styles of Prospective Kickboxing Coaches According to the Variable of Years of Doing Sports

\begin{tabular}{|c|c|c|c|c|c|c|}
\hline & $\begin{array}{lll}\text { Years } & \text { Of } & \text { Doing } \\
\text { Sports } & & \\
\end{array}$ & $\mathbf{N}$ & $\mathbf{X}$ & Ss & $\mathbf{F}$ & $\mathbf{p}$ \\
\hline \multirow[t]{4}{*}{ Self-Esteem } & $1-5$ Years & 14 & 10,64 & 1,44 & 1,51 & 0,22 \\
\hline & 6-10 Years & 25 & 10,56 & 1,00 & & \\
\hline & 11 Years and Above & 23 & 10,00 & 1,47 & & \\
\hline & Total & 62 & 10,37 & 1,30 & & \\
\hline \multirow[t]{4}{*}{ Careful } & 1-5 Years & 14 & 10,64 & 1,54 & 1,56 & 0,21 \\
\hline & $6-10$ Years & 25 & 9,32 & 2,11 & & \\
\hline & 11 Years and Above & 23 & 9,95 & 2,73 & & \\
\hline & Total & 62 & 9,85 & 2,28 & & \\
\hline \multirow[t]{4}{*}{ Avoidant } & 1-5 Years & 14 & 2,50 & 2,17 & 2,13 & 0,12 \\
\hline & $6-10$ Years & 25 & 3,00 & 2,73 & & \\
\hline & 11 Years and Above & 23 & 4,00 & 1,75 & & \\
\hline & Total & 62 & 3,25 & 2,33 & & \\
\hline \multirow[t]{4}{*}{ Postponing } & 1-5 Years & 14 & 3,92 & 2,49 & 3,08 & 0,05 \\
\hline & $6-10$ Years & 25 & 2,56 & 1,60 & & \\
\hline & 11 Years and Above & 23 & 3,69 & 1,84 & & \\
\hline & Total & 62 & 3,29 & 1,98 & & \\
\hline \multirow[t]{4}{*}{ Panic } & 1-5 Years & 14 & 2,71 & 2,09 & 0,67 & 0,51 \\
\hline & $6-10$ Years & 25 & 2,68 & 1,97 & & \\
\hline & 11 Years and Above & 23 & 3,34 & 2,34 & & \\
\hline & Total & 62 & 2,93 & 2,13 & & \\
\hline
\end{tabular}

Table 3. Distribution Values of Decision Making Styles of Prospective Kickboxing Coaches According to the Variable of Education

\begin{tabular}{|c|c|c|c|c|c|c|}
\hline & Education & $\mathbf{N}$ & $\mathbf{X}$ & Ss & $\mathbf{t}$ & $\mathbf{p}$ \\
\hline \multirow[t]{2}{*}{ Self-esteem } & High School & 20 & 10,40 & 1,31 & 0,12 & 0,90 \\
\hline & University & 42 & 10,35 & 1,32 & & \\
\hline \multirow[t]{2}{*}{ Careful } & High School & 20 & 10,05 & 2,39 & 0,46 & 0,64 \\
\hline & University & 42 & 9,76 & 2,26 & & \\
\hline \multirow[t]{2}{*}{ Avoidant } & High School & 20 & 3,40 & 2,56 & 0,32 & 0,74 \\
\hline & University & 42 & 3,19 & 2,24 & & \\
\hline \multirow[t]{2}{*}{ Postponing } & High School & 20 & 3,85 & 2,36 & 1,54 & 0,12 \\
\hline & University & 42 & 3,02 & 1,74 & & \\
\hline \multirow[t]{2}{*}{ Panic } & High School & 20 & 3,00 & 2,31 & 0,16 & 0,87 \\
\hline & University & 42 & 2,90 & 2,06 & & \\
\hline
\end{tabular}

In the evaluation of the t-test analysis results according to education variable in Table 3, the decision making styles were observed in mean scores of self-esteem, careful, avoidant, postponing and panic subscales $(p<0.05)$ and no significant difference was observed.

\section{Discussion and Conclusion}

This section includes the discussion and interpretation about whether the self-esteem in decision making and decision making styles of prospective kickboxing coaches differ according to their personal characteristics.

According to the age variable of prospective kickboxing coaches in evaluation of the results of variance analysis about the scores of self-esteem in decision making and decision making styles scales, it was observed that there was no significant difference in terms of self-esteem in decision making (I. section) and decision making styles, which include careful decision making, avoidant decision making, panic decision making and postponing decision making, and the age variable ( $<<0.05$, Table 1). Evaluating similar studies, in a study conducted by Demirbaş (1992), it was reported that there was an increase in decision making skills with increased age and decisions were more binding. In a study conducted by Özcan (1999) investigating managers in high schools for their decision making styles, it was reported that managers between 36-40 years old evaluated options in the decisions making process more sensibly compared to managers between 25-30 years old as well as managers between 41-45 years old compared to managers between 20-25 years old. In a study conducted by Alver (2003), it was determined that individuals' decision making styles did not differ according to their ages. In a study conducted by Arn (2006) by utilizing the Decision Strategies Scale of Kuzgun (1992) investigating decision making styles of managers in high schools, it was determined that no decision making style differed according to age variable, except for the style of dependent decision making. In the Ph.D. dissertation conducted by Hulderman (2003) and Sanders (2008), it was determined that the decision making styles of individuals did not constitute a significant difference in terms of their age groups. Similar findings of previous studies support our study.

According to the education variable of prospective kickboxing coaches, investigating the results of variance analysis 
regarding self-esteem in decision making and decision making styles scale scores, the mean scores of self-esteem in decision making (I. section) and decision making styles, the subscales of decision making styles, careful decision making, avoidant decision making, avoidant decision making, postponing decision making and panic decision making did not constitute a significant difference in terms of academic staff's variable of education level $(p<0.05)$.

In the evaluation of various studies, Uzunoğlu (2008) conducted a study with Turkish football referees and reported that there were differences in scores of avoidant decision making style, one of the subscales of decision making styles, according to their education level. The study also further determined that the significant difference was between referees with high school degrees and those with master's degrees and graduate degrees from the School of Physical Education and Sports. In Özcan's (1999) study, no significant difference was observed in the decision making styles of school managers according to their education level. In the Ph.D. study conducted by Kao (2005), it was determined that there was a significant difference in managers' mean scores in rational, dependent, avoidant and self-instant decision making styles according to their education levels. In a study conducted by Yiğit (2005), it was determined that the students with high level of academic success used more sensible decision making strategies compared to students with moderate and low levels of academic success. In the results of the study conducted by Sanders (2008), it was determined that decision making styles of individuals did not significantly differ according to their education levels.

According to the prospective kickboxing coaches' variable of years of doing sports, investigating the variance analysis regarding the scores of self-esteem in decision making and decision making styles scales, it was determined that there was no significant difference in academic staff's self-esteem in decision making (I. section) and mean scores of avoidant decision making style, postponing decision making style and panic decision making style, which are subscales of decision making styles, according to their years of working as academics ( $p<0.05)$.. In a study conducted by Özcan (1999) investigating the decision making styles of managers in high schools, it was determined that managers with a total professional experience of 21-25 years evaluated options more carefully in decision making and evaluated positive and negative aspects of each option more carefully compared to managers with professional experiences of 1-5 years and 16-20 years. Additionally, it was further determined that managers with professional experience of $1-5$ years believed that their emotions would lead them to the truth more and had higher mean scores of leaning towards desired option compared to managers with professional experience of 6-10 years. In the Ph.D. studies conducted by Hulderman (2003) and Kao (2005), it was reported that individuals' decision making styles did not significantly differ according to their period of total experiences.

As a result of the study, no statistically significant difference was observed in the comparison of mean scores of decision making and decision making styles according to participants' variables of age, gender and years of doing sports. It was observed that coaches' self-esteem in decision making levels were significantly higher.

Considering the results of the study, the following suggestions can be made.

- By conducting courses and seminar programs for ensuring that coaches are aware of their own decision making styles, it can be stated that coaches can act in accordance with their decision making styles and develop skills to solve problems experienced in a better way.

- By means of courses and seminars, younger coaches who have less professional experience are believed to gain qualifications such as experience of learning based on groups or cooperation, higher levels of socialization, working with other and dealing with problems about them etc.

\section{References}

Alver, B. (2003). The Relationship between empatic skills, decision strategies and psychological symtoms of employees, Ataturk University, Institute of Social Sciences, Department of Educational Sciences, Ph.D. Thesis, Erzurum.

Arin, A. (2006). A Study of Relationship Between Instructional Leadership and Decision Making and Problem Solving Strategies of Secondary School Principals, Eskisehir Osmangazi University, Institute of Social Sciences, Department of Educational Sciences, Department of Educational Management, Inspection, Planning and Economics, M. A Thesis, Eskisehir.

Carney, C. C. W. (1995). Discover the Career Within You, New York Brook/Cole, Publishing Company

Cimen, A. (1999). Decision Making Timsah Publishing, İstanbul.

Clemen, R. T., \& Reilly, T. (2001). Making Hard Decisions with Decision Tools. New York: Duxbury Thomson Learning.

Demirbas, H. (1992). Comparison of Decision Making Behaviors of Guilty and Non-Guilty Adolescents M.A Thesis, Ankara University Institute of Social Sciences, Ankara.

Deniz, M. E. (2002). A Study of Comparison of University Students Decision Making Strategies and Social Skill Levels with Respect to Ta-Dominant Ego States and Some Self Qualities (Published Ph.D. Thesis). Selcuk Univeristy Institute of Social Sciences. Konya. 
Deniz, M. E. (2004). A study on the Investigation of Self-Esteem, Decision Making Styles and Problem Solving Skills of University Students in Decision Making Journal of Education Research, 15, 23-35.

Ersever, H. O. (1996). The Effects of Gaining Decision Making Skills Program and Interaction Group Experience on The Decision Making Styles of University Students, (Unpublished Ph.D. Thesis). Ankara University Institute of Social Sciences. Ankara.

Hulderman, A. M. (2003). Decision-Making Styles and Learning Strategies of Police Officers: Implications for Community Policing, Oklahoma State University, Faculty of the Graduate College of the Oklahoma State University, Doctorate Thesis, Oklahoma.

Hulderman, A. M. (2003). Decision-Making Styles and Learning Strategies of Police Officers: Implications for Community Policing, Oklahoma State University, Faculty of the Graduate College of the Oklahoma State University, Doctorate Thesis, Oklahoma.

Kao, H. P. (2005). Taiwanese Executive's Leadership Styles and Their Preferred Decision-Making Models Used in Mainland China, The University of the Incarnate Word, The School of the Graduate Studies of The University of the Incarnate Word, Doctorate Thesis, Texas.

Kokdemir, D. (2003). Decision Making in Uncertainty Situations and Problem Solving, (Unpublished Ph.D. Thesis). Ankara University Institute of Social Sciences. Ankara

Kuzgun, Y. (1992). Decision Strategies Scale: Development and Standardization VII. Scientific Studies of National Psychological Congress. Turkish Psychologist Association. p, 161-170. Ankara.

Kuzgun, Y. (2000). Profession Consultancy” Nobel Publishing. Ankara.

Norfolk, D. (1989). Stress in Business life Translation: Leyla, Serdaroglu). Form Publication. Istanbul.

Ormand, C., \& Ark, (1991). A Metacognitive Analysis of Decision Making in Adolescence. Journal of Adolescence, 14(3), 275-291. https://doi.org/10.1016/0140-1971(91)90021-I

Ozcan, K. (1999). Decision Making Process and Anxiety Level of Administrators, Marmara University, Institute of Social Sciences, Department of Technology Education, M.A Thesis, İstanbul.

Payne, W. J., Bettman R. J., \& Johson, J. E. (1993). The Adaptive Decision Maker. Cambridge: Cambridge University Press. https://doi.org/10.1017/CBO9781139173933

Phillips, S. D., Pazienza, N. J., \& Ferrin, H. H. (1984). Decision-Making Styles and Problem-Solving Appraisal. Journal of Counseling Psychology, 31, 497-502.

Phillips, S. D., Pazienza, N. J., \& Walsh, D. (1984). Decision-Making Styles and Progress in Occupational Decision Making. Journal of Vocational Behavior, 25, 96-105. https://doi.org/10.1016/0001-8791(84)90039-3

Sanders, R. P. (2008). The Decision-Making Styles, Ways of Knowing, and Learnıng Strategy Preferences of Clients At a One-Stop Career Center, Southern Oklahoma State University, Faculty of the Graduate College of the Oklahoma State University, Doctorate Thesis, Stillwater, Oklahoma.

Shiloh, S., Koren, S., \& Zakay, D. (2001). Individual Differences in compensatory decision Making Style Hit2 and Need For Closure as Correlates of Subjective Decision Complexity and Difficulty, Personality and Individual Differences. https://doi.org/10.1016/S0191-8869(00)00073-8

Sinangil, K. H. (1993). The Relationship between Decision making and Anxiety of Manager Candidates VII. Scientific Studies of National Psychological Congress. Turkish Psychologists Association Publication. Ankara.

Temel, V. (2010). Comparison of leadership styles of individuals who practice individual and team coaching in the city of Konya M.A Thesis, Karaman: Karamanoglu Mehmetbey University Institute of Social Sciences.

Terakya, G. (1998). Relationship between Patients and Nurses Zirve Printing, 5. Edition, p.134-141. Ankara.

Tiryaki, S., Erdil, G., Acar, M., \& Emlek, Y. (1991). Personality Characteristics of Athletes and Non-Athlete Youngsters SHD. 26, 19-23.

Ulukan, M. (2006). Role of coaches in football players' dedication to their clubs Ph.D. Thesis, Konya: Konya Selcuk University Institute of Social Sciences. http://www.kickboks.gov.tr/KickboksTarihcesi.html12.04.2018 00:44

Yigit, A. (2005). Prediction of High School Students' Decision Making Behaviors by Some Variables, Ege University Institute of Social Sciences Department of Guidance and Psychological Consultancy, M.A Thesis, Izmir.

Yigit, A. (2005). Prediction of High School Students' Decision Making Behaviors According to Some Variables Ege University Institute of Social Sciences Department of Guidance and Psychological Consultancy, M.A Thesis, Izmir.

\section{Copyrights}

Copyright for this article is retained by the author(s), with first publication rights granted to the journal.

This is an open-access article distributed under the terms and conditions of the Creative Commons Attribution license which permits unrestricted use, distribution, and reproduction in any medium, provided the original work is properly cited. 